\title{
Qualidade seminal, morfologia dos testículos e epidídimos de touros submetidos à dieta contendo gossipol
}

\author{
[Seminal quality, testicle and epididymis morphology of bulls fed a \\ diet containing gossypol] \\ M.D. Santos ${ }^{1}$, R.S. Rodrigues ${ }^{1}$, S.H. Freitas ${ }^{1}$, D.S. Costa $^{2}$, J.R.M. Ruas ${ }^{3}$, \\ E.J. Miranda ${ }^{4}$, M.J. Simões 5 \\ ${ }^{1}$ Aluno de pós-graduação - Universidade de Cuiabá - Unic - Faculdade de Medicina Veterinária - Cuiabá, MT \\ ${ }^{2}$ Faculdade de Medicina Veterinária e Zootecnia - UFMS - Campo Grande, MS \\ ${ }^{3}$ Epamig -Belo Horizonte, MG \\ ${ }^{4}$ Universidade Federal do Mato Grosso - UFMT - Cuiabá, MT \\ ${ }^{5} \mathrm{EPM}$ - Unifesp - São Paulo, SP
}

\begin{abstract}
RESUMO
Objetivou-se avaliar o efeito da ingestão de gossipol livre sobre a qualidade espermática e a morfologia dos testículos e dos epidídimos de touros da raça Nelore. Doze touros receberam dieta contendo 3,3g de gossipol livre/touro/dia (caroço de algodão) (Grupo 1, n=6) e dieta isenta de gossipol (Grupo 2, n=6), respectivamente. Foram realizadas coletas de sêmen no início e no final do experimento, que teve duração de 73 dias. Ao final do estudo, foram retirados os testículos e os epidídimos dos touros para se estudar o efeito do gossipol livre sobre as características histológicas. O consumo médio de 3,3g de gossipol livre/touro/dia (média 7,1 mg de gossipol livre/kg/dia) reduziu a motilidade e a concentração espermática e aumentou a porcentagem de defeitos espermáticos maiores e totais. Além disso, os animais apresentaram testículos com túbulos seminíferos de menor espessura de parede, menor número de camadas de células espermatogênicas, menor espessura do epitélio epididimário e menor número de espermatozoide no interior dos ductos epidídimários, em relação aos animais com dieta isenta de gossipol (Grupo 2). O consumo de 3,3g de gossipol livre/touro/dia acarretou alterações na morfologia e na morfometria dos testículos e dos epidídimos e reduziu a qualidade espermática dos touros.
\end{abstract}

Palavras-chave: caroço de algodão, histomorfometria, qualidade espermática

\begin{abstract}
The objective was to evaluate the effect of intake of free gossypol on sperm quality and morphology of the testicles and epididymis of Nelore bulls. Twelve bulls were fed diets containing $3.3 g$ of free gossypol/bull/day (cottonseed) (Group 1, $n=6$ ) and a diet free of gossypol (Group 2, $n=6$ ), respectively. Semen samples were collected in the beginning and end of the experiment which lasted 73 days. In the end of the study the testes and epididymis of bulls were removed to study the effect of free gossypol on histological characteristics. The average consumption of $3.3 \mathrm{~g}$ of free gossypol/bull/day (mean $7.1 \mathrm{mg}$ of free gossypol/kg/day) reduced motility and sperm concentration and increased the percentage of major and total sperm defects, as well as the animals showing testes with seminiferous tubules of smaller thickness, fewer layers of spermatogenic lineage cells, smaller epididymal epithelium thickness and smaller number of sperm within the epididymal ducts, compared to animals with a diet free of gossypol (Group 2). The consumption of $3.3 \mathrm{~g}$ of free gossypol/bull/day led to changes in morphology and morphometry of the testes and epididymis and reduced sperm quality of bulls.
\end{abstract}

Keywords: cottonseed, histomorphometry, sperm quality

Recebido em 3 de março de 2012

Aceito em 6 de março de 2013

E-mail: dinizms@uol.com.br 


\section{INTRODUÇÃO}

Nos últimos dez anos, um dos maiores responsáveis por manter crescente a balança comercial foi o agronegócio, que responde por 90\% das reservas cambiais brasileiras (Camargo, 2011). O estado de Mato Grosso tem como base econômica o seu potencial agropecuário, sendo detentor do maior rebanho bovino do país, com 28.695.273 cabeças (Indea, 2011). Também é o maior produtor de algodão herbáceo (Gossypium hirsutum) do país, com área plantada de 392,4 mil hectares e produção de $1.559,8$ mil toneladas (safra 2009/2010) (Conab, 2010). Tais condições têm estimulado muitos pecuaristas e empresas da área de nutrição a utilizarem os subprodutos do algodão, em especial o caroço, na alimentação animal, dada a sua oferta no mercado, o seu valor energético, proteico e o baixo preço.

Nas raízes, folhas, caule e sementes do algodão, existem glândulas que produzem um pigmento polifenólico de cor amarela, tóxico, denominado gossipol. Seu efeito tóxico é acarretado pelo gossipol livre, parte do gossipol que é solúvel em acetona. O teor de gossipol livre no caroço de algodão normalmente é semelhante ao teor total, podendo restringir sua utilização na alimentação de ruminantes e não ruminantes (Randel et al., 1992; Santos, 1997). A concentração de gossipol na semente de algodão varia amplamente com os genótipos da planta, podendo apresentar plantas com ausência de gossipol e até com $9 \%$ do peso da semente (Jorge, 2006).

Estudos relataram que o gossipol livre interfere na fertilidade de touros, reduzindo a qualidade seminal e aumentando as patologias espermáticas (Vinne, 1992; Chenoweth et al., 1994; Hassan et $a l ., 2004)$ decorrentes de alterações morfológicas nos túbulos seminíferos (Arshami e Ruttle, 1988; Santos et al., 2008). Vinne (1992) relatou que touros produziram sêmen de qualidade reduzida ao ingerirem 2 e $4 \mathrm{~g}$ de gossipol livre diariamente, o que sugere que reprodutores com acesso a alimentação com caroço de algodão podem ser menos férteis.

Chase et al. (1994) forneceram dietas contendo caroço de algodão (16g de gossipol livre/touro/dia), farelo de algodão $(1,8 \mathrm{~g}$ de gossipol livre/touro/dia) e farelo de soja (isento de gossipol) no período de desmama até a puberdade. Observaram que os animais alimentados com caroço de algodão atingiram idade à puberdade mais tardiamente em relação aos submetidos às dietas contendo farelo de soja. $\mathrm{O}$ gossipol afetou a morfologia testicular, mas não reduziu a qualidade espermática dos touros à puberdade.

Observam-se dados controversos na literatura com relação aos efeitos do gossipol sobre a fertilidade animal, e no Brasil as informações disponíveis sobre o teor de gossipol no caroço de algodão e seu efeito tóxico sobre a reprodução animal ainda são bastante incipientes. Portanto, o objetivo deste estudo foi avaliar a qualidade espermática e a histomorfometria dos testículos e dos epidídimos de touros submetidos às dietas com ou sem gossipol livre.

\section{MATERIAL E MÉTODOS}

Todas as técnicas e os procedimentos realizados nesta pesquisa foram aprovados pelo Comitê de Ética em Pesquisa da Universidade Federal de São Paulo - Unifesp, protocolo 0663/10.

Doze touros da raça Nelore, com média de 30 meses de idade e $443,7 \pm 14,9 \mathrm{~kg}$ de peso vivo, aptos à reprodução, foram utilizados neste estudo. Os animais foram distribuídos aleatoriamente em dois grupos: Grupo 1 (G1, $\mathrm{n}=6$ ), que recebeu dieta contendo caroço de algodão (gossipol), e Grupo 2 (G2, n=6), que recebeu dieta sem gossipol. O teor de gossipol livre contido no caroço de algodão, utilizado na dieta dos animais, foi determinado por cromatografia líquida de alta performance (HPLC), no Laboratório de Análises Químicas Lab Tec (Hortolândia - SP), obtendo-se valor médio de $1,9 \mathrm{~g}$ de gossipol livre/kg de caroço de algodão.

Os touros foram mantidos nos seus respectivos grupos, em área confinada, com média de $25 \mathrm{~m}^{2}$ /animal, com bebedouros e cochos para mistura mineral e para volumoso.

Para formulação das dietas, amostras dos alimentos foram coletadas, e foram determinadas a composição química e a dos nutrientes. As exigências nutricionais foram estabelecidas de acordo com Valadares Filho et al. (2006), para ganhos estimados de 1,4kg/animal/dia, contendo, na matéria seca, 12,5 e $11,5 \%$ de proteína bruta (PB); 74,6 e 74,0\% de nutrientes digestíveis 
totais (NDT); e 8,0 e $6,0 \%$ de extrato etéreo (EE), para os animais do G1 e G2, respectivamente. As dietas (Tab. 1) foram pesadas e fornecidas ad libitum duas vezes ao dia, às sete e às 17 horas, por 73 dias. Antes das sete horas eram realizadas a limpeza dos cochos e a pesagem das sobras, para se obter o consumo animal.

Avaliou-se o ganho de peso dos animais por 57 dias, pois não foram considerados os 16 dias de fase de adaptação dos animais às dietas, sendo estes sempre pesados pela manhã, antes do fornecimento da primeira refeição.

A qualidade espermática dos touros foi determinada no início e ao final da fase experimental, via eletroejaculação, avaliando-se o percentual de motilidade espermática progressiva retilínea, a concentração espermática (número de espermatozoides x $10^{6} / \mathrm{mL}$ de sêmen) e o percentual de defeitos espermáticos menores, maiores e totais conforme descrito por Henry e Neves (1998).

Posteriormente ao abate dos animais em frigorífico, foi realizada a orquiectomia, e fragmentos do parênquima testicular e da cauda do epidídimo de cada touro foram fixados por imersão em solução de Bouin por um período de 24 horas. Logo após, os fragmentos foram submetidos à desidratação em série crescente de etanol (70 a 100\%), seguida da diafanização com xilol, impregnados e incluídos em parafina à temperatura de $59^{\circ} \mathrm{C}$. Os cortes de $5 \mu \mathrm{m}$ foram obtidos em micrótomo, submetidos à coloração H.E. (hematoxilina-eosina), para avaliação das estruturas testiculares e epididimárias dos animais (Grupos 1 e 2), respectivamente.

Tabela 1. Composição média das dietas fornecidas aos touros com caroço de algodão (G1) e sem caroço de algodão (G2)

\begin{tabular}{lccccc}
\hline Alimentos & MS & G1 & \multicolumn{3}{c}{} \\
& $(\%)$ & MS $(\mathrm{kg})$ & MN $(\mathrm{kg})$ & MS $(\mathrm{kg})$ & $\mathrm{MN}(\mathrm{kg})$ \\
\hline Silagem de milho & 28 & 3,68 & 13,14 & 3,68 & 13,14 \\
Milho grão & 88 & 3,08 & 3,50 & 3,08 & 3,50 \\
Caroço de algodão & 92 & 2,10 & 2,28 & & \\
Resíduo de soja & 90 & 1,05 & 1,17 & 1,05 & 1,17 \\
Farelo de arroz & 90 & 0,53 & 0,59 & 2,63 & 2,92 \\
Sal mineral & 95 & 0,07 & 0,07 & 0,07 & 0,07 \\
\hline Total & & 10,51 & 20,75 & 10,51 & 20,75 \\
\hline
\end{tabular}

Foram escolhidos aleatoriamente 10 túbulos seminíferos dos testículos de cada animal dos Grupos 1 e 2 para se avaliar a espessura da parede, sendo mensurado $(\mu \mathrm{m})$ o diâmetro horizontal de cada túbulo e subtraído do diâmetro do respectivo lúmen, dividindo-se por dois para se obter a medida da espessura da parede do túbulo no sentido horizontal. O mesmo procedimento foi utilizado no sentido vertical, obtendo se, assim, por média, a espessura da parede de cada túbulo seminífero e o número de camadas celulares. Esse procedimento foi também utilizado para se avaliarem os ductos epididimários da cauda do epidídimo. Foi utilizado sistema computadorizado composto por um microscópio óptico, em aumento de 400x, adaptado com câmera de alta resolução (ICC50, Leica Microsystems, São Paulo, SP) com monitor de vídeo colorido, para mensuração morfométrica das referidas estruturas.
A qualidade espermática, as morfometrias testicular e epididimária e o ganho de peso foram submetidos à análise de variância, e as médias comparadas pelo teste F, utilizando-se o programa SAEG - Sistema de Análises Estatísticas e Genéticas (Sistema..., 1997).

\section{RESULTADOS E DISCUSSÃO}

Os animais do G1 consumiram menos alimentos (média de $15,8 \mathrm{~kg} /$ dia na matéria natural), em relação aos G2 (média de $22,3 \mathrm{~kg} /$ dia na matéria natural $)(\mathrm{P}<0,05)$. Possivelmente isto ocorreu em função da concentração estimada de lipídeo (EE) na matéria seca das dietas, que foi de $8 \%(\mathrm{G} 1)$ e 6\% (G2), respectivamente. O teor de lipídeo acima de $6 \%$, na matéria seca, da dieta total de ruminantes pode reduzir o consumo de alimentos, por interferir na fermentação ruminal e reduzir a digestibilidade (Palmquist, 1994). Provavelmente esse fato acarretou menor ganho 
médio de peso pelos animais do G1 $(43,8 \pm 12,9)$ em relação aos do $\mathrm{G} 2(66,2 \pm 12,8)(\mathrm{P}<0,05)$, pois as médias dos pesos inicial e final dos touros do G1 foram de 444,0 $\pm 18,0$ e 487,8 $\pm 20,3 \mathrm{~kg}$ e do G2 de $443,3 \pm 12,1$ e $509,5 \pm 17,3 \mathrm{~kg}$, respectivamente, obtidos durante 57 dias de avaliação.

Considerando-se o consumo médio diário de alimentos realizado pelos touros do G1 (média de $15,8 \mathrm{~kg} / \mathrm{dia}$, na matéria natural), tendo-se estimado inicialmente para esses animais um consumo de 20,7 kg/touro/dia (MN), contendo $2,3 \mathrm{~kg}$ de caroço de algodão $(\mathrm{MN})$, obtém-se um consumo médio diário de $1,75 \mathrm{~kg}$ de caroço de algodão/touro/dia (MN), contendo $1,9 \mathrm{~g}$ de gossipol livre/kg de caroço de algodão, o que resultou em um consumo médio estimado de $3,3 \mathrm{~g}$ de gossipol livre/touro/dia (média de 7,1mg de gossipol livre/kg/dia).

Houve redução na motilidade espermática progressiva $\quad(\mathrm{P}<0,01)$, na concentração espermática $(\mathrm{P}<0,05)$ e aumento no percentual de defeitos espermáticos maiores e totais $(\mathrm{P}<0,01)$ dos animais que consumiram dieta contendo $3,3 \mathrm{~g}$ de gossipol livre/touro/dia em relação aos submetidos à dieta sem gossipol (Tab. 2), tendo como principais defeitos espermáticos o de peça intermediária e o da cauda fortemente dobrada. Vinne (1992) também relatou que touros produziram sêmen de qualidade reduzida ao ingerirem 2 a $4 \mathrm{~g}$ de gossipol livre diariamente. Chenoweth et al. (1994) observaram que o consumo de $8,2 \mathrm{~g}$ de gossipol livre/dia reduziu a porcentagem de espermatozoides normais em touros jovens da raça Brahman, tendo como principal defeito espermático o de peça intermediária, que possivelmente acarretou redução na motilidade espermática e na fertilidade. Contrariamente, Chase et al. (1994), ao fornecerem dietas contendo caroço de algodão (16g de gossipol livre/touro/dia), relataram que o gossipol afetou a morfologia testicular, mas não reduziu a qualidade espermática dos touros à puberdade.

Em concordância com os dados obtidos neste estudo, Hassan et al. (2004) relataram que a ingestão de $8 \mathrm{mg}$ de gossipol livre/kg de peso vivo acarretou aumento nas anormalidades espermáticas em touros na fase peripuberal, sendo esse processo reversível 150 dias após o término da ingestão.

Tabela 2. Efeito das dietas com gossipol (G1) e sem gossipol (G2) sobre motilidade progressiva e concentração espermática, defeitos espermáticos menores, maiores e totais dos touros no início e no final do experimento

\begin{tabular}{|c|c|c|c|c|}
\hline & \multicolumn{2}{|c|}{ Início } & \multicolumn{2}{|c|}{ Final } \\
\hline & G1 & G2 & G1 & $\mathrm{G} 2$ \\
\hline $\begin{array}{l}\text { Motilidade espermática } \\
(\%)\end{array}$ & $65,0 \pm 7,74$ & $67,5 \pm 6,12$ & $52,5 \pm 11,72 \mathrm{a}$ & $73,3 \pm 4,08 b^{* *}$ \\
\hline $\begin{array}{l}\text { Concentração } \\
\text { espermática }\left(\times 10^{6} / \mathrm{mL}\right)\end{array}$ & $836,6 \pm 103,85 a$ & $993,3 \pm 72,57 b^{*}$ & $578,3 \pm 141,19 \mathrm{c}$ & $1105,0 \pm 152,80 \mathrm{~d} * *$ \\
\hline $\begin{array}{l}\text { Defeitos espermáticos } \\
\text { menores }(\%)\end{array}$ & $7,7 \pm 1,50$ & $6,5 \pm 1,04$ & $10,8 \pm 2,78 \mathrm{a}$ & $8,0 \pm 1,26 b^{*}$ \\
\hline $\begin{array}{l}\text { Defeitos espermáticos } \\
\text { maiores }(\%)\end{array}$ & $13,2 \pm 1,60$ & $14,7 \pm 2,16$ & $16,0 \pm 1,26$ a & $12,3 \pm 1,36 b^{* *}$ \\
\hline $\begin{array}{l}\text { Defeitos espermáticos } \\
\text { totais }(\%)\end{array}$ & $20,8 \pm 1,47$ & $21,2 \pm 1,83$ & $26,8 \pm 3,18$ a & $20,3 \pm 1,75 b^{* *}$ \\
\hline
\end{tabular}

Médias com diferentes letras na mesma linha diferem entre si. ${ }^{*} \mathrm{P}<0.05,{ }^{* * *} \mathrm{P}<0.01$.

Os touros do Grupo 1 apresentaram túbulos seminíferos com menor número de camadas de células da linhagem espermatogênica, menor espessura de sua parede e menor espessura média do epitélio do epidídimo (cauda) $(\mathrm{P}<0,01)$ (Tab. 3). Os epidídimos dos animais pertencentes ao Grupo 2 (dieta isenta de gossipol) encontravam-se constituídos por túbulos enovelados com paredes formadas externamente por fibras musculares lisas, dispostas de forma helicoidal, e internamente por um epitélio pseudoestratificado com estereocílios, apresentando no seu lúmen inúmeros espermatozoides. No Grupo 1, obtevese a mesma arquitetura histológica observada no G2, no entanto, aparentemente, observou-se menor quantidade de espermatozoide no seu interior e epitélio pseudoestratificado menos desenvolvido. 
Qualidade seminal...

Tabela 3. Efeito das dietas com gossipol (G1) e sem gossipol (G2) sobre as características morfométricas dos epidídimos e dos testículos dos touros

\begin{tabular}{llcc}
\hline Discriminação & & $\mathrm{G} 1$ & $\mathrm{G} 2$ \\
\hline Espessura média do epitélio do epidídimo $(\mu \mathrm{m})$ & & $25,78 \pm 7,32 \mathrm{a}$ & $65,20 \pm 5,42 \mathrm{~b}$ \\
Número médio de camadas de células da linhagem & $2,71 \pm 1,21 \mathrm{a}$ & $5,25 \pm 1,32 \mathrm{~b}$ \\
espermatogênica & & $52,43 \pm 8,63 \mathrm{a}$ & $63,32 \pm 6,58 \mathrm{~b}$ \\
\hline
\end{tabular}

Médias com diferentes letras na mesma linha diferem entre si $(\mathrm{P}<0,01$; teste $\mathrm{F})$.

Ficou evidenciado neste estudo que a ingestão de $3,3 \mathrm{~g}$ de gossipol livre/touro/dia $(7,1 \mathrm{mg}$ de gossipol livre $/ \mathrm{kg} / \mathrm{dia}$ ) acarretou redução de 48,4\% no número de camadas de células espermatogênicas, de $17,2 \%$ na espessura da parede dos túbulos seminíferos e de $60,5 \%$ na espessura do epitélio do epidídimo, em relação aos touros com dieta isenta de gossipol (G2) (percentuais obtidos dos dados da Tab.3), reduzindo a qualidade espermática (Tab.2) e, possivelmente, a fertilidade de touros. As alterações na morfometria testicular também foram evidenciadas por Arshami e Ruttle (1988). Já Sullivan et al. (2010) forneceram farelo de algodão contendo $1,2 \mathrm{~g}$ de gossipol na fase prénatal de fêmeas bovinas e não observaram alterações testiculares nos touros oriundos dessa gestação. A fim de reforçar a necessidade de maiores estudos nesta área, Burns et al. (2010) relatam que, devido à falta de pesquisas na região norte da Austrália, o farelo e o caroço de algodão continuam sendo utilizados sem restrições na suplementação alimentar de bovinos.

A recomendação de utilização de até $3,2 \mathrm{~kg}$ de caroço de algodão/animal/dia (matéria natural) (Poore e Rogers, 1995) está bem acima da utilizada neste estudo, mas foi suficiente para acarretar alterações nos parâmetros morfométricos epididimário e testicular e redução na qualidade espermática dos touros. Vale ressaltar que a concentração de gossipol na semente de algodão varia amplamente com os genótipos da planta (Jorge, 2006). Portanto, esse fator deve ser levado em consideração na realização de pesquisas afins, para não acarretar prejuízos reprodutivos e produtivos aos animais.

Acredita-se que a maior porcentagem de espermatozoide anormal e as alterações morfométricas ocorridas nos túbulos seminíferos e epidídimos dos touros submetidos à dieta com gossipol podem reduzir a fertilidade dos animais, sendo, portanto, importante estudar o comprometimento da fertilidade dos touros sobre a reprodução das fêmeas.

\section{CONCLUSÕES}

O consumo de 3,3g de gossipol livre/touro/dia acarretou alterações na morfometria dos testículos e dos epidídimos e reduziu a qualidade espermática dos touros.

\section{REFERÊNCIAS}

ARSHAMI, J.; RUTTLE, J.L. Effects of diets containing gossypol on spermatogenic tissues of young bulls. Theriogenology, v.30, p.507-516, 1988

BURNS, B.M.; FORDYCE, G.; HOLROYD, R.G. A review of factors that impact on the capacity of beef cattle females to conceive, maintain a pregnancy and wean a calf-Implications for reproductive efficiency in northern Australia. Anim. Reprod. Sci., v.122, p.1$22,2010$.

CAMARGO, A. Canal do produtor. O agronegócio $e$ o sucesso do Brasil no mercado de carnes, 2011. Disponível em: <http://www.canaldoprodutor.com.br/ comunicacao/artigos/oagroneg\%C3\%B3cio-e-osucesso-do-brasil-no-mercado-de-carnes>. Acessado em: 19 nov. 2011.

CHASE, C.C.; BASTIDAS, P.; RUTTLE, J.L. et al. Growth and reproductive development in Brahman bulls fed diets containing gossypol. J. Anim. Sci., v.72, p.445-452, 1994.

CHENOWETH, P.J.; RISCO, C.A.; LARSEN, R.E. et al. Effects of dietary gossypol on aspects of semen quality, sperm morphology and sperm production in young Brahman bulls. Theriogenology, v.42, p.1-13, 1994.

CONAB Companhia Nacional de Abastecimento. Série Histórica da cultura do algodão, 2010. Disponível em: <http://www.conab.gov.br/conabweb/ index.php?PAG=131>. Acessado em: 10 mar. 2010. 
HASSAN, M.E.; SMITH, G.W.; RANDALL, S.O. et al. Reversibility of the reproductive toxicity of gossypol in peripubertal bulls. Theriogenology, v.61, p.1171-1179, 2004.

HENRY, M.; NEVES, J.P. 2.ed. Manual para exame andrológico e avaliação de sêmen animal. Belo Horizonte: CBRA, 1998. 49p.

INDEA Instituto de Defesa Agropecuária do Estado de Mato Grosso. Campanha de vacinação de combate à Febre Aftosa, 2011. Disponível em: <http://www.indea.mt.gov.br/html/noticia.php?codigo Noticia $=1392 \& f$ assunto $=\& f$ data $=0>$. Acessado em: 27 dez. 2011

JORGE, S.A.F. Estudo da adsorção do gossipol existente em óleo de semente de algodão. 2006. 72f. Dissertação (Mestrado em Tecnologia de Alimentos) Universidade Federal do Ceará, Fortaleza.

PALMQUIST, D.L. The role of dietary fats in efficiency of ruminants. J. Nutr., v.124, p.1377-1382, 1994.

POORE, M.H.; ROGERS, G. Feeding whole cottonseed and other cotton by-products to beef cattle. Vet. Med., v.90, p.1077-1087, 1995.
RANDEL, R.D.; CHASE, C.C.; WYSE, S.J. Effects of gossypol and cottonseed products on reproduction of mammals. J. Anim. Sci., v.70, p.1628-1638, 1992.

SANTOS, R.L. Efeitos do gossipol sobre a reprodução. Cad. Tec. Esc. Vet., v.21, p.73-82, 1997.

SANTOS, M.D.; PORTILHO, C.B.K.F.; RUAS, M.R.J. et al. Morfologia testicular e qualidade espermática de touros da raça Nelore, submetidos à dieta contendo gossipol. Rev. Bras. Cienc. Vet., v.15, p.134-139, 2008.

SISTEMA de análises estatísticas e genéticas - SAEG. Versão 7.1. Viçosa: UFV, 1997. 150p.

SULLIVAN, T.M.; MICKE, G.C.; GREER, R.M. et al. Dietary manipulation of Bos indicus $\times$ heifers during gestation affects the prepubertal reproductive development of their bull calves. Anim. Reprod. Sci., v.118, p.131-139, 2010.

VALADARES FILHO, S.C.; PAULINO, P.V.R.; MAGALHÃES, K.A. Exigências nutricionais de zebuínos e tabelas de composição de alimentos BRcorte. 1.ed. Viçosa: UFV, 2006. 142p.

VINNE, J.U.V.D. Alimentação de gado. Quanto de semente de algodão é muito? Rev. Batavo, v.9, p.2021, 1992. 